\title{
1. Regulating competition in the digital economy
}

\author{
With a special focus on platforms
}

\section{Björn Lundqvist}

\section{INTRODUCTION}

The perceived lack of competition and the apparent power of platforms in the digital economy are currently triggering the attention of politicians, businessmen, the academic community and, even, the general public. The groups are concerned for different reasons. Businessmen see an opportunity for the creation of wealth being lost behind large barriers to entry, erected by the system leaders controlling the platforms; politicians view with unease the rise of fake news on large social sites and everyone acknowledges that the collection and use of personal data and artificial intelligence to make purchase and business decision for individuals and businesses is a paradigm shift in how the liberal economy functions.

There is an intense academic discussion regarding whether consumers and business users are exposed to conduct that may amount to competition law abuses when using services on the Internet. The discussion is connected to the Internet phenomenon of 'platforms' or intermediaries, i.e. Internet sites where users and potential purchasers of services and products are matched and interact with advertisers, business users, service providers or suppliers. Indeed, the rise in importance of platforms - as an intermediary - in all branches of industry is obvious to everyone. ${ }^{1}$ Yet, the consequences of this shift are not clear, and the issue which this chapter will address is whether competition law is currently adapted to deal with the perceived problems of platforms.

1 There are several forms of platforms, especially, when taking into consideration the Internet of Things and the Industrial Internet. See Geoffrey G. Parker, Marshall W. van Alstyne and Sangeet Paul Choudary, Platform Revolution: How Networked Markets Are Transforming the Economy and How to Make Them Work for You (W.W. Norton, New York, 2017). 
Internet platforms may, due to certain special and somewhat unique characteristics, like network effects, tipping and path dependency, become central 'hubs' in the digital value chain between purchasers and suppliers. The economists seem to tell us that only a limited number of platforms may exist on the Internet. ${ }^{2}$ Hubs in separate large ecosystems consist of a main service, the platform, and several connected neighbouring sites providing services or goods. ${ }^{3}$ Well-known ecosystems mainly focused on marketing against consumers are the Google and the Amazon ecosystems, while there are also Industrial Internet platforms and ecosystems being developed.

In each ecosystem, a platform constitutes the central arrangement in the digital value chain between business users and consumers. The multitude of direct customer-supplier transactions making up everyday business conduct are, to an increasing degree, replaced on the Internet by an intermediary, the platform, matching the customer with the supplier. Platforms are able to do so because they provide efficient and easy matching. Choice is reduced on platforms since consumers/users to a higher degree delegate the purchasing decisions to intermediaries, abdicating the need to stay informed to be able to take the right commercial and business decisions by handing over the relevant personal and non-personal data to intermediaries to make or simplify the decision for them. The platform, by predicting what the customer wants, makes a selection of what products or services it provides to the customer. Finally, this set-up creates lock-in effect, where both businesses, by making use of platforms providing customers, and individuals, by supplying their data and delegating commercial decisions to the platforms, will become dependent on the intermediaries to make decisions for them. Indeed, in the end, the platform will pre-deliver the product or service before even the customer has placed the order, so-called 'anticipatory shipping'. ${ }^{4}$

This chapter will - without any attempt to discuss all issues - sketch a framework for how to address platforms under competition law, i.e. on what levels or dimensions do they conduct their business and compete, what exclusionary unilateral practices are relevant in the digital economy, and, hence, should they be prohibited under competition law when taking into consideration legal and economic theory?

The chapter specifically focuses on the application of competition law vis-à-vis the platforms collecting personal and non-personal data. May com-

2 Jacques Crémer, Yves-Alexandre de Montjoye and Heike Schweitzer, 'Competition policy for the digital era', Final report (2019) 5, available at http://ec .europa.eu/competition/publications/reports/kd0419345enn.pdf accessed 1 July 2019.

3 See Parker et al. (n 1).

4 See Amazon patent for anticipatory shipping, https://patents.google.com/patent/ US8615473B2/en. 
petition law be used to gain access to the intermediaries, and the infrastructure around that data? ${ }^{5}$ And, may competition law be used to limit the inherent effect of creating strong platforms and 'hubs' in the digital economy.

Thereafter, the chapter will raise the issue of sector-specific regulation in the arena of data. Fair commercial terms is not only a disputed issue under 'general' competition law, but is also discussed in reference to sector-specific regulations such as the Public Sector Information (PSI) Directive ${ }^{6}$ and the eCall Regulation, ${ }^{7}$ also in the field of financial services ${ }^{8}$ and in reference to e-platforms ${ }^{9}$ and the free flow of data. ${ }^{10}$ Indeed, it seems that rules regarding certain conduct by platform providers, regarding for example the use and access of data (ex ante regulations) are currently seeping in as sector- or industry-specific regulations, implying an obligation to either share data or to grant open and somewhat non-discriminatory access to platforms and devices which collect the data. ${ }^{11}$

5 In reference to Open Data see Josef Drexl, 'The Competition Dimension of the European Regulation of Public Sector Information and the Concept of an Undertaking', in: Drexl, J. and Bagnoli, V. (eds), State-Initiated Restraints of Competition (ASCOLA Competition Law, Edward Elgar Publishing, 2015) 64-100. See also Björn Lundqvist, " "Turning Government Data into Gold": The Interface Between EU Competition Law and the Public Sector Information Directive - With Some Comments on the Compass Case' (2013) 44(1) International Review of Intellectual Property and Competition Law 79.

6 Directive 2003/98/EC on the re-use of public sector information [2003] OJ L 345/90 (known as the 'PSI Directive') entered into force on 31 December 2003.

7 Regulation (EU) 2015/758 concerning type-approval requirements for the deployment of the eCall in-vehicle system based on the 112 service and amending Directive 2007/46/EC [2015] OJ L 123/77.

8 In order to accelerate retail banking innovation and simplify payments, the European Commission is mandating standardised API access across the EU. The initiative is part of the European Commission's update of the Directive on Payment Services (PSD). The revision to the Directive on Payment Services (PSD2) requires banks to provide access to third parties. See Directive (EU) 2015/2366 on payment services in the internal market, amending Directives 2002/65/EC, 2009/110/EC and 2013/36/EU and Regulation (EU) No. 1093/2010, and repealing Directive 2007/64/EC (Text with EEA relevance) [2015] OJ L 337/35. Cf. EU Commission, 'A Digital Single Market Strategy for Europe', COM(2015) 192 final.

9 The proposed P2B Regulation: Brussels, 26.4.2018 $\operatorname{COM}(2018) 238$ final 2018/0112 (COD) Proposal for a regulation on promoting fairness and transparency for business users of online intermediation services.

10 There are French national initiatives to open e-platforms for third-party competitors. See e.g. French Senate Report (20 March 2013) available at http://www.senat.fr/ rap/r12-443/r12-443.html accessed 1 July 2019.

11 Alex Chisholm and Nelson Jung, 'Platform Regulation - Ex-ante versus Ex-post Intervention: Evolving Our Antitrust Tools and Practices to Meet the Challenges of a Digital Economy' (Spring-Autumn 2015) 11(1) Competition Policy International 7. 
The chapter concludes that general competition law may not be readily applicable for the conduct of platforms at its current stage of development. To create or uphold competition, competition law needs to develop new tools and tests and while competition law, given the time to do so, may develop well-balanced new tests, sector-specific regulations seem to be the preferred choice to create instant competition easy fixes for legislators. However, enacting new legislation regulating industry without thoughtful analysis of the consequences may prove disastrous. Indeed, the legislator should wait for competition doctrine to develop and preferably utilise the tools available under competition law such as updating or creating new forms of group exemptions, instead of enacting ex ante sector-specific legislation.

\section{THE REGULATION OF PLATFORMS AND THEIR INFRASTRUCTURE, I.E. THEIR ECOSYSTEM}

Generally, the platform business activities are directly or indirectly perceived today under competition law as being conducted on three different 'levels' and even though there are overlaps, perceiving the industry in levels works quite well.

At the first level, there is the competition between platforms or ecosystems, i.e. 'inter-platform' or inter-ecosystem competition. The system leaders controlling ecosystems and successful platforms compete by adopting new services, innovating new systems for attracting attention. While the competition at this level seems fierce, there are incidents which might amount to competition law violations. For example, platform providers regularly exclude or restrict access to competing platform providers on their respective platforms. ${ }^{12}$

At the second level, there is a relevant academic discussion regarding the restraints the system leaders of the platforms or ecosystems burden the business users connected to their respective ecosystem. Indeed, 'intra-platform' or 'intra-ecosystem' competition is a relevant notion where the system leaders might hold power vis-à-vis business users that view the system leader's ecosystem as indispensible for their business activities. Business users wanting to

12 See, for example, the Google and Amazon feud, which ended with a truce regarding streaming technology and features. 'Google will let Amazon have a real YouTube app on its Fire TV platform', and Amazon will expand Prime Video support to Chromecast and all Android TV devices. Reg Whitwam, 'Amazon, Google Finally End YouTube Streaming Feud' (18 April 2019), https:/www.extremetech.com/internet/ 289858-amazon-google-finally-end-youtube-streaming-feud accessed 19 July 2019. See also Spotify complaint to the European Commission regarding 'the Apple tax', https:/techcrunch.com/2019/03/13/spotify-files-a-complaint-against-apple-with-the -european-commission-over-apple-tax-and-restrictive-rules accessed 19 July 2019. 
be recognised and present in the ecosystem and on the central platform need to agree on terms and conditions that might cause exclusion of competition and could amount to competition law violations.

Thirdly, the creation, collection, storing, commercial use, and dissemination of data, be it government (open) data and/or private (big) data, ${ }^{13}$ are rapidly increasing and should be perceived as a new dimension or level where competition between firms may take place. For a firm to compete with data a number of components must be present. For the data industry to materialise, someone needs to invest in the collection and storing of data. Until lately, a government authority or similar body has usually been the data collector. Hence, a public sector body, based on an obligation in law, collecting necessary data for society concerning, for example, land ownership, trademarks, weather information, maps or company data and storing the data on servers, has up until recently been the 'normal' data collector. While these public collectors have gradually, voluntarily or under for example the European PSI Directive started to market the data to consumers on the Internet and to firms re-using the same (e.g. data brokers or data re-users), private parties, with a few exceptions, until recently have had neither the interest nor the means to collect and store vast amounts of data in a similar way. ${ }^{14}$

However, with Google, Amazon and Facebook being the pioneers, private entities are clearly starting to collect and store large volumes of data, both non-personal and personal (consumer) data. ${ }^{15}$ Private parties, active online

13 The definition of Big Data is vague and lacks precision, see Andrea De Mauro, et al., 'A Formal Definition of Big Data Based on Its Essential Features' (2016) 65(3) Library Review 122, 122-135, available at http://www.emeraldinsight.com/doi/ pdfplus/10.1108/LR-06-2015-0061122-135.

${ }_{14}$ OECD, 'Data-Driven Innovation - Big Data for Growth and Well-Being' (2015) available at http://www.oecd.org/sti/ieconomy/data-driven-innovation.htm accessed 23 April 2018; OECD, 'Big Data - Bringing Competition Policy to the Digital Era' (2016) available at http://www.oecd.org/daf/competition/big-data-bringing-competition -policy-to-the-digital-era.ht accessed 23 April 2018. The German and French Competition Authorities joint paper, 'Competition Law and Data' (10 May 2016), available at http://www.autoritedelaconcurrence.fr/doc/reportcompetitionlawanddatafinal .pdf accessed 23 April 2018. See also regarding Open Data, Björn Lundqvist, Marc de Vries, Emma Linklater, and Lisa Rajala Malmgren, 'Business Activity and Exclusive Right in the Swedish PSI Act', (Swedish Competition Authority, September 2011), available at http://www.konkurrensverket.se/globalassets/english/publications-and -decisions/business-activity-and-exclusive-right-in-the-swedish-psi-act.pdf accessed 23 April 2018.

15 Google is involved in several investigations in several jurisdictions regarding the company's business conduct. See e.g. the Commission Statement of Objections to Google on Android operating system and applications, 20 April 2016. Cf. EU Commission, Press Release, Statement of Objections to Google on Android operat- 
selling ads or space, or, more accurately, access to avenues and matching service (interoperability) for the marketing of goods or services by business users to potential consumers, have realised that it may be profitable to collect personal data. Mainly consumer data, but also other forms of information and knowledge are collected. These firms want to be able to sell focused matching services or avenues that, with the use of the collected user data and algorithms, pinpoint the most likely purchasers and also warrant that the commercial message penetrates and reaches the intended focus groups. ${ }^{16}$ However, the collection of non-personal data is increasing rapidly within the Industrial Internet and in connection to Internet of Things (IoT).

Thus, at the third level, firms now compete with data. In reference to data, several platforms, Internet sites, devices and machines are already equipped with sensors to collect data and devices may run software to control and make interoperable the functioning of machines, but also to enable the interoperable and personal smart kitchens, vehicles, and even cities. The system leaders of these smart interoperable systems may act as gatekeepers, controlling and locking in customers, while excluding or limiting interoperability with other systems, specific devices or machine-producing firms and customers, based on the access, use and reuse of data. The technique for excluding firms could be contractual, technical (based on private or privileged private application programming Interfaces (APIs)), or superior data access and control. Indeed, the system leaders may compete by hoarding data and not give access to other business users in the ecosystem. The restraints may at a first glance be seen as vertical, but, may, at a closer look be horizontal since the system leader is either vertically integrated or the restrictions aim to fend off possibly potential or system-related competition. Indeed, access to up-to-date data (nowcasting ${ }^{17}$ ) may often blurr the boundaries of markets and also the divide between horizontal, vertical, and conglomerate, while diminishing the difference between inter- and intra-ecosystem competition.

Device producers in this setting, being, often, old economy brick-and-mortar firms, should, thus, strive to compete on a somewhat level playing field with

ing system and applications (20 April 2016) available at http://europa.eu/rapid/press -release_IP-16-1492_en.htm accessed 23 April 2018.

16 ibid.

17 Nowcasting is the capacity of a company to use the velocity at which a dataset grows to discern trends before others do. Nowcasting enables a firm not only to track trends in users' conduct in real time, but also to monitor trends in (potential) competitors' conduct, and to respond more quickly, which helps it push or nudge the market. Daniel Rubinfeld and Michal Gal, 'Access Barriers to Big Data' (2017) 59 Arizona Law Review, 339 available at SSRN: https://ssrn.com/abstract=2830586 or http://dx .doi.org/10.2139/ssrn.2830586, accessed 12 December 2018. 
the system leaders, and try to avoid being excluded and degraded to suppliers or unequal partners of the platform, while the system leaders control the ecosystem and obtain all relevant data from the customers, suppliers, and competitors of the brick-and-mortar firm. ${ }^{18}$ This, however, implies that these firms need to become more innovative and create their own platforms and ecosystems. Indeed, a possibility for brick-and-mortar firms to challenge the hubs, i.e. the platforms and intermediaries is to collaborate in data pools and joint platforms.

Would this imply that competition in the digital economy should be left to be played out, and that neither the business strategies regarding access, non-access and use of data employed by the system leaders should be viewed as anticompetitive and violating competition law? This depends on the identification of dominance and antitrust harm.

For the above-described conduct to amount to an abuse of dominance, the system leader (or platform) needs to be considered dominant. This issue has been discussed intensely in academia, and will only be sparsely discussed in this chapter.

For the first level, the platform v. platform competition, the issue is to identify relevant market power. The business models for platforms is different: some sites focus on retail, connecting sellers and purchasers for purchasing products and services; some platforms are social sites, e.g. dating sites, while others focus on general and vertical search. ${ }^{19}$ Several of the platforms and ecosystems compete intensely, while still providing a conglomerate portfolio of services. They generally, thus, compete for users' and consumers' limited attention span, ${ }^{20}$ while still being active in specific downstream or aftermarkets. $^{21}$

The second, and to some extent third level described above, concerns (eco) system competition. Firms compete with the system leaders and with each other on the down-, upstream or aftermarkets in relation to the hub of the ecosystem, the platform. The thesis is that a system leader that has been able

18 Björn Lundqvist, 'Cloud services as the ultimate gate(keeper)' (2019) Journal of Antitrust Enforcement, available at https://doi.org/10.1093/jaenfo/jny013 accessed 15 July 2019.

19 There exist several different platforms. See Crémer et al. (n 2).

20 Tim Wu, 'Blind Spot: The Attention Economy and the Law' (2017) Antitrust Law Journal, available at SSRN: https://ssrn.com/abstract=2941094 or http://dx.doi .org/10.2139/ssrn.2941094, accessed 22 July 2019.

21 The concept of aftermarket should be used with caution. Aftermarkets give rise to several kinds of questions under competition law. For example, does a relevant market for competitive analysis consist of separate markets for primary and secondary products, or is it a market for 'systems' consisting of both primary and secondary products? 
to utilise network externalities and economies of scale and restrict data flows can tip the specific platform market, so that consumers for the platform service turn to the system leader's platform. The system leader would then be able to control the platform with the thereto connected ecosystem - a central arrangement in the network for scares resources - and gain market power inside that network, to a point where the system leader becomes a 'winner takes all or most' of the welfare generated by that network (or that ecosystem). In essence, the system leader 'rules' the ecosystem.

\section{DOMINANCE IN THE DIGITAL ECONOMY}

Under the classical methodology using relevant market and the SSNIP test, it is difficult to identify market power in the digital economy. Among platforms, Google and Facebook have been identified as holding market power due to the popularity of their respective sites/ecosystems with their users. ${ }^{22}$ Nonetheless, it is increasingly acknowledged that controlling data is key in the ability of firms to gain and hold market power. ${ }^{23}$ Access to and instant control

22 See for example the EU Commission discussion regarding the market power of Google search in Case AT.39740 Google Search (Shopping), 27 June 2017, and the German Competition Authority, Case B6-22/16 Facebook, 07.02.2019, https://www .bundeskartellamt.de/SharedDocs/Meldung/EN/Pressemitteilungen/2019/07_02_2019 Facebook.html.

${ }^{23}$ For example, the German Competition Act was amended in 2017, stating that 'access to relevant data are a potential source of market power'. See also, e.g. Wolfgang Kerber, 'Digital Markets, Data, and Privacy: Competition Law, Consumer Law, and Data Protection' (2016) Gewerblicher Rechtsschutz und Urheberrecht. Internationaler Teil 639-647 available at http://dx.doi.org/10.2139/ssrn.2770479 accessed 13 July 2018. There are several authors who maintain that holding big data does not equate to market power. See e.g. Guiseppe Colangelo and Mariateresa Maggiolino, 'Big Data as Misleading Facilities', Bocconi Legal Studies Research Paper No. 2978465 (2017) available at http://dx.doi.org/10.2139/ssrn.2978465 accessed 13 July 2018. Generally, they argue that big data does not create a significant barrier to entry and they base their claims, inter alia, on the non-exclusive and non-rivalrous nature of data and a claimed ease of collecting it, while disregarding many potential entry barriers. Other scholars argue that the harm created by big data relates mainly to privacy. Yet, these conclusions are based on the limited existing economic studies on big data, which often focus on one specific market (most commonly on search engines or personal data markets). See e.g. Rubinfeld and Gal (n 17). Darren S. Tucker and Hill B. Wellford, 'Big Mistakes Regarding Big Data' (2014) 6(10) Antitrust Source; Maureen K. Ohlhausen, and Alexander Okuliar, 'Competition, Consumer Protection, and the Right [Approach] To Privacy' (2015) 80(121) Antitrust Law Journal; James C. Cooper, 'Privacy and Antitrust: Underpants Gnomes, the First Amendment, and Subjectivity' (2013) 20(1129) George Mason Law Review. 
of vast amounts of data ${ }^{24}$ creates competitive advantages for firms. The firm having the best and most timely access and control over the largest and best data-sets should be able to utilise this to learn about the market and customers, personalise products and gain a leading market position. In the current stage of development of the digital society, platforms are the main collectors of data, while also being bottlenecks and central administrative units in the networks they create. The system leaders are able to detach the direct customer-supplier interface, which is replaced by the intermediary, the platform. That implies that the platform not only acts as a retail service, it also collects and transfers commercial data regarding purchasers, products and suppliers. Secondly, the platforms provide, and will increasingly provide, an appreciated service since to a high degree they gain the trust to conduct or simplify the purchasing decisions for consumers. Purchasers abdicate the need to stay informed by handing over the relevant personal and non-personal data to intermediaries to make or simplify the business decisions for them. The platforms will, in the end, hold the information and knowledge relevant to make the best informed decisions, and will be able to make connections not visible at first. The platforms will be able to do this by enacting search procedures which de facto reflect a constant Research and Development procedure. They utilize a 'try and error' to understand the personal preferences of each customer.

With the advance of the IoT, the amount of data that will be collected will increase immensely, also in industries that previously were not digital. Regular brick-and-mortar industry is likely to start including data-collecting sensors in the production of new products and within the products, and will, hence, become data collectors. The collected data will either be generated by the users of these products or devices, or by other devices when IoT components will start communicating with each other. Further, future product markets will face a paradigm shift when data are included in the value chain. ${ }^{25}$ The vast amounts of collected data will influence the way the products are designed and developed, increase product quality, which in turn should generate best-matched

24 There is a discussion regarding the definition of 'data': does it encompass syntactic information, semantic information, or both; and where should one draw the line in reference to protecting 'data'? See Josef Drexl, 'Designing Competitive Markets for Industrial Data - Between Propertisation and Access' (2016) 16-13 Max Planck Institute for Innovation \& Competition Research Paper 12 et seq. available at http://dx .doi.org/10.2139/ssrn.2862975 accessed 12 July 2019.

${ }_{25}$ ibid. See also OECD, Big Data - Bringing Competition Policy to the Digital Era (2016) http://www.oecd.org/daf/competition/big-data-bringing-competition -policy-to-the-digital-era.htm accessed 13 July 2018; Autorité de la Concurrence and Bundeskartellamt, Competition Law and Data (2016), 7, 10 et seq. http://www .autoritedelaconcurrence.fr/doc/reportcompetitionlawanddatafinal.pdf accessed 13 July 2018 
products to buyers' expectations, as revealed by the data. ${ }^{26}$ Indeed, continuously data collection implies R\&D development in collaboration with the firms connected to the system. This could alter old economy markets from being mainly focused on marginal cost and efficiency, to become data and innovation driven. It is further feasible that old oligopolistic markets will be transformed when one firm wins the data-driven competition ('winner takes most') and becomes the system leader of specific systems, e.g. smart kitchens, vehicles. Indeed, the suppliers of individual devices to the systems, e.g. to the smart kitchen, may be excluded and degraded to suppliers or unequal partners of the system leader controlling the main platform. Oligopolistic 'old economy' markets will become semi-monopolistic markets, inhabited by system leaders, due to indirect network effects, learning effects and tipping controls ecosystems. This includes dependent suppliers and systems that can withstand attacks even from disruptive innovations. ${ }^{27}$

The services provided by Amazon, Google and other platforms, e.g., transaction sites, cloud services, may constitute an example of the problem of few platforms controlling data and possibly gaining market power due to the data-driven business model. It is not uncommon that Amazon, Google and other platforms have access to most, if not all, data generated in their respective ecosystems, while the business users in each ecosystem have limited access to data generated by them in the ecosystem. The platform providers may, through their services and the collection of data, hold the knowledge of several industries, and with this advantage in data, they can eventually understand and learn business users' markets, even though not being an active member of those markets. This may lead the system leaders to vertically integrate. They have data advantage vis-à-vis the incumbent brick-and-mortar firms, and utilise data not only to become the hubs of the ecosystem, but to produce product and devices on regular product markets.

The question is whether being a system leader and obtaining data from several participants in a market could amount to holding system market power, while not being active on those specific product markets. Could control of data flows correspond to market power in the ecosystem and thereto connected markets? ${ }^{28}$ Or could a system leader having access to data from the majority

\footnotetext{
26 Rubinfeld and Gal (n 17).

27 Jens Prüfer and Christoph Schottmüller, 'Competing with Big Data' (CentER Discussion Paper; Vol. 2017-007), Tilburg: CentER, Center for Economic Research.

28 See the US Kodak case, Eastman Kodak Co. v. Image Technical Servs., Inc., 504 U.S. 451 (1992), where the Court held that even though an equipment manufacturer lacked significant market power in the primary market for its equipment copier-duplicators and other imaging equipment - nonetheless it could have sufficient market power in the secondary aftermarket for repair parts to be liable under the anti-
} 
of the firms active on a downstream market, be considered dominant in the upstream data market?

Establishing market power in reference to the digital economy raises many questions. The identification of dominance should also take into consideration the direct and indirect network effects, network externalities and the high risk of market tip in favour of one firm. On the other hand, firms who have gained a 'winner takes most' position may still fall foul of a 'death spiral' where they lose both consumer and business users, breaking down the network because both groups trigger each other. However, such breakdown would be based on some kind of collective and transparent decision from, at least, a substantial group of users of one side of the network to leave the network, which seems to be rare, and difficult to organise. High-quality data and better usability (predictive modelling tools), combined with a data-driven business model, may also quickly create and sustain dominance or even a monopoly position since the system leader would be more informed of the needs of the users of the platform. ${ }^{29}$

With Industrial Internet, it may be common for data to be collected and stored with the system leader in the relevant Industrial Internet ecosystem, with the systems leader having entered into vertical agreements with business users in its ecosystems. The aim of these vertical agreements may vary, but generally is benign, while an ancillary restraint may be that the data or traffic produced by the business users in the system is shared or even exclusively belongs to the system leader. It seems that often the system leader gives access to the data, but only to a few firms in the ecosystem. It thus gives access to its users' data to third parties arbitrarily or in a discriminating fashion, vis-à-vis the users. ${ }^{30}$

For example, Uber and some other e-ecosystems have a business idea where the system leader collects exclusively the data generated by their users busi-

trust laws for its exclusionary conduct in the aftermarket. For the EU see the Hugin case, Hugin Kassaregister AB and Hugin Cash Registers Ltd v. EU Commission, Case 22/78, ECLI:EU:C:1979:138.

${ }_{29}$ Prüfer and Schottmüller, (n 27). See also CASE AT.39740 Google Search (Shopping), 27 June 2017 and European Commission, Commission Staff Working Document Impact Assessment, Accompanying the document Proposal for a Regulation of the European Parliament and of the Council on a framework for the free flow of non-personal data in the European Union, SWD/2017/0304 final - 2017/0228 (COD), Brussels, 13 September 2017 (Impact Assessment); Commission Staff Working Document on the free flow of data and emerging issues of the European data economy, $\operatorname{COM}(2017) 9$ Final, 10 January 2017.

30 Lundqvist (n 18) 
ness (the drivers), while the drivers do not have a right to port the data from their customers should they wish to exit the Uber system. ${ }^{31}$

Given the above, there seem to be indications that system leaders may have power to control their ecosystems. However, do they hold market power? Generally, given the methodology applied above - to divide the digital economy in three levels - would imply that at the first level, inter platform competition, platform market power should be identified in the relationship with other platforms. This might, however, pose a problem since the platforms that we know seem to be very different. Amazon, Google and Facebook are providing different services. Some scholars are suggesting that they are indeed not so different and are competing on a general attention market. ${ }^{32}$ They are fighting for our eyes and interests. How much attention do users give certain platforms and ecosystems in reference to other forms of media and intermediaries? Can market power be identified based on the time spent on a platform in relation to other platforms? Can users be locked in to certain ecosystems and devote most of their attention to them? Can we identify and suggest market power based on the level of attention a media is gaining? Or, do we still need to identify 'markets'? In the few cases where competition authorities have scrutinised the digital economy, the courts seem to instead find the platform service provided and even though being free of charge, identify this as a relevant market. See for example the Google cases, identifying general search as a relevant market. ${ }^{33}$ However, perhaps there is - on top of this - a general attention market where the platforms compete, irrespective of the different services they provide, and where neither platform could be considered as having a monopoly or a dominant position.

At the second level, inter ecosystem competition, the system leader could have monopoly power and dominance within ecosystems, even though dominance cannot be identified at the first level. ${ }^{34}$ The core activities of the platforms and the theories of network effect, learning effects and the ease that certain services 'tip' needs also to be taken into consideration both for inter-

31 ibid. The EU Commission has recognised this problem in the proposed platform to business regulation (P2B), which stipulates a rule that a platform provider must be transparent with the data it collects from its business users and if it intends to limit access to business users and give access to that data to its business users in a discriminating fashion. It needs to inform its business users, be transparent, about its business intent. European Commission, Fairness in platform-to-business relations, Ref. Ares (2017) 5222469 - 25/10/2017.

$32 \mathrm{Wu}(\mathrm{n} 20)$.

33 Case AT.39740 Google Search (Shopping), 27 June 2017.

34 Crémer et al. (n 2). See also Eastman Kodak Co. v. Image Technical Servs., Inc., 504 U.S. 451 (1992). For the EU see the Hugin case, Case 22/78 Hugin Kassaregister AB and Hugin Cash Registers Ltd $v$ EU Commission, ECLI:EU:C:1979:138. 
and intra-ecosystem competition. The theory of path dependency could be utilised to show that both purchasers and business users of ecosystems may over time become dependent and locked in to certain networks, making the ecosystem or network the relevant arena for judging whether the system leaders hold power, or not. Indeed, the initial decision in favour of one ecosystem means that a large number of follow-on decisions are de facto already taken and little competition exists on this level. This concerns all products within the ecosystem, from apps to further devices. For these parts, products and services, the influence of users is reduced to a minimum. The initial purchase comes at the cost of high path dependency for all further individual decisions. Institutional economics characterise such situations as situations of path dependence. ${ }^{35}$

Data could increase the network and learning effects, and be part of the dominance analysis, while data still also can be a separate third level where power can be identified. Firms controlling data flows from several sources connected to the same market may have some degree of control and power on these markets and system leaders have power controlling data in the ecosystem.

Given the discussion in this chapter, a line of reasoning that could be pursued is that dominance in reference to the digital economy, and, specifically, in reference to platforms could be based on a direct analysis of the service provided by the platform and its connected ecosystem. The platforms of today in several aspects generally provide the service of interoperability to the users, while also having one core service where the platform often attracts the majority of users. There is a general consensus among many in academia that interoperability of network industries often migrate towards one solution. ${ }^{36}$ Interoperability tech-

35 Cf. Douglass C. North, 'Economic Performance Through Time' (1994) 84(359) American Economic Review; Stan Liebowitz and Stephen E. Margolis, 'Path Dependence, Lock-In, and History' (1995) 11(205) Journal of Law, Economics and Organization; Leonhard Dobusch and Elke Schüßler, 'Theorizing Path Dependence: A Review of Positive Feedback Mechanisms in Technology Markets, Regional Clusters and Organizations (2013) 22(617) Industrial and Corporate Change. See also Rupprecht Podszun, 'Innovation, Variety \& Fair Choice - New Rules for the Digital Economy: Expert Opinion for Finanzplatz München Initiative' (FPMI 2017) available at SSRN: https://ssrn.com/abstract=3243403 or http://dx.doi.org/10.2139/ssrn.3243403 accessed 19 July 2019.

36 Several researchers have discussed this. See Carl Shapiro and Hal R. Varian, Information Rules (Harvard Business School Press 1999) 173 et seq. See also Neil Gandal, 'Compatibility, Standardization, and Network Effects: Some Policy Implications' (2002) 18 Oxford Review of Economic Policy, 80; Michael Katz and Carl Shapiro, 'Systems Competition and Network Effects' (1994) 8 Journal of Economic Perspective 93; Mark Lemley and David McGowan, 'Legal Implications of Network Economic Effects' (1998) 86 California Law Review 479; Michael Schallop, 'The IPR Paradox: Leveraging Intellectual Property Rights to Encourage Interoperability in the Network Computing Age' (2000) 28 AIPLY Quarterly Journal, 195; Mark Lemley, 
nology or services migrate towards one solution since network effects require that the only efficient solution is to have one service for the network. At least if the solution is able to create network effects and, the platform-service win and tip the service market in its favour.

The EU Commission's research report seems to mirror this line of thinking, where it indicated that system leaders are regulators within their ecosystems. ${ }^{37}$ Indeed, platform service provision could hence be identified as an infrastructure type of service that should be available on fair reasonable and non-discriminatory (FRAND) terms. Or, the mere knowledge that network effect often will only provide one solution in reference of services of interoperability type can create a rebuttable presumption of dominance when analysing platforms.

Moreover, the platform service market, when tipping has occurred, can be defined as 'failed' from a competition viewpoint. When network effect has been able to tip the market in favour of one semi-monopolist, it is unlikely that competition for that service can create the benefits inherent in the competitive process. Competition law must then be used to create competition within the platform-connected ecosystem.

The above analysis can possibly be conducted without the need for in-depth analysis of fluid relevant markets, and could be a more straightforward analysis, focusing on the problems platforms are perceived to create. The conclusion could be that platforms providing these services should be regarded as regulators of said ecosystems and networks. There will be little - if no - competition for that network and the system leader therefore has a special responsibility to create a level playing field under the platform for downstream, upstream and connected markets. ${ }^{38}$ This could imply far-reaching responsibilities for the system leaders.

'Intellectual Property Rights and Standard-Setting Organizations' (2002) 90 California Law Review, 1889, 1896 et seq.

37 ' $[\mathrm{I}] \mathrm{t}$ is equally important to protect competition on a dominant platform (which in many cases might be the same as protecting competition "in" the market). In this respect, we argue that platforms play a form of regulatory role as they determine the rules according to which their users, including consumers, business users and providers of complementary services, interact, and, when they are dominant, have a responsibility to ensure that competition on their platforms is fair, unbiased, and pro-users.' Jacques Crémer, Yves-Alexandre de Montjoye and Heike Schweitzer, 'Competition policy for the digital era', Final report (2019), 5 et seq, available at http://ec.europa.eu/ competition/publications/reports/kd0419345enn.pdf accessed 1 July 2019.

38 Crémer et al. (n 2), 69 et seq., available at http://ec.europa.eu/competition/ publications/reports/kd0419345enn.pdf accessed 1 July 2019. 


\section{CONDUCT THAT IS ANTICOMPETITIVE}

The more difficult issue is whether a platform may be considered in violation of Article 102 Treaty on the Functioning of the European Union (TFEU) by having a data advantage and leveraging that advantage to further its market dominance. The advantage in data may originate from a contractual right to access and use customers' data, and while such a clause may be considered anticompetitive in certain situations, a data advantage may be caused without the use of specific potentially anticompetitive clauses in the agreement. How should the structural problems of too much data in the hands of too few e-ecosystem leaders be handled? Or, more accurately, can competition law fix the problem of data-driven business models that create monopolies by using network externalities and tipping? The competition arising from rivalry between system leaders provide different types of problems.

The challenges of the services in the digital economy are the underlying consequences of indirect (or direct) network effects and tipping. However, to implement a data-driven business model or make use of network effects cannot in itself be anticompetitive. Antitrust harms and effects need to be identified. As case law stands today, it seems clear that anticompetitive harm focuses on exclusionary effects caused by the conduct of the dominant firm, outside the realm of competition on the merits. ${ }^{39}$ The important initial issue is to identify the antitrust harm with reference to the business conduct. What is the problem to competition? Unfair behaviour when platforms compete does not have to be anticompetitive; this depends on the definition of competition and harm. ${ }^{40}$

Interestingly, in the digital economy it seems that the most likely anticompetitive behaviour of platform providers would be discriminatory exclu-

39 See Case C-413/14 P Intel v. Commission ECLI:EU:C:2017:632, and Case C-209/10 Post Danmark ECLI:EU:C:2015:651. On the exceptional circumstance doctrine, cf. Joined Cases C-241/91 and C-242/91 RTE, ITP \& BBC v. Commission ECLI: EU:C:1995:98 (Magill) etc.

40 Ariel Ezrachi and Maurice Stucke, 'Artificial Intelligence \& Collusion: When Computers Inhibit Competition', Oxford Legal Studies Research Paper No. 18/2015; University of Tennessee Legal Studies Research Paper No. 267 (April 8, 2015). Available at SSRN: http://ssrn.com/abstract=2591874 or http://dx.doi.org/10.2139/ ssrn.2591874 accessed 23 April 2018. Ariel Ezrachi and Maurice Stucke, Virtual Competition The Promise and Perils of the Algorithm-Driven Economy, (Harvard University Press, 2016); Maurice Stucke and Allen Grunes, Big Data and Competition Policy (1st Edition, OUP, 2016). See also Allan Grunes and Maurice Stucke, 'No Mistake About It: The Important Role of Antitrust in the Era of Big Data Antitrust Source Online', University of Tennessee Legal Studies Research Paper No. 269 (28 April 2015) available at SSRN: http://ssrn.com/abstract=2600051 accessed 28 February 2018. 
sionary practice, such as not generally giving access to some business users, while leveraging the power of the platform downstream onto other users' brick-and-mortar markets. Indeed, intra ecosystem restraints on competition seem more relevant then inter platform competition. 'Vertical' restraints may be considered anticompetitive. Discrimination on behalf of the Internet intermediary, in relation to the platform or the data collected, enabling an Internet intermediary or a proxy to leverage onto the market of a business user, might also fall under Article 102 TFEU. The system leader would collect and give access to data or the result of predictive modelling to a specific firm, while refusing access to others, to enable that firm to leverage the data advantage against existing competitors. This could be seen as anticompetitive, creating discriminatory exclusion (cf. Article 102 c TFEU). ${ }^{41}$

In reference to Internet intermediaries, it might be useful to instate and prohibit a general form of leveraging abuse achieved by exclusive or discriminatory use of data. Such leveraging abuse would require identification of the dominant firm, by itself or through a proxy, leverage onto a secondary (brick-and-mortar) market by giving itself or a proxy advantages through increased access to data, so that an exclusionary effect on the competitive secondary market materialises, and by foreclosing an equal efficient existing competitor, by not granting access to said data.

In the EU, leveraging is considered relevant often in combination with other forms of abuses, for example, tying, marginal squeezing or refusal to supply. However, leveraging can be viewed as a broad underlying stand-alone

${ }^{41}$ There are some similar French cases: the French Competition Authority imposed an interim measure on GDF, ordering the gas supplier to grant its competitors access to some of the consumer data, in particular consumption data, it collected as a provider of regulated offers (on the gas market). The aim of this interim measure was to allow all suppliers to have the same level of relevant data to make competitive offers to consumers for gas and electricity (no public information or third-party private database existed on households subscribing to gas contracts). French Competition Authority, Decision 14-MC-02 of 09.09.2014. Due to privacy laws, the transmission of GDF data to competitors was conditional on approval by consumers. A significant proportion of the consumers did refuse that their data be transferred from GDF to competing operators. The case is discussed in German and French Competition Authorities (n 14) 20. French Competition Authority, Decision n ${ }^{\circ} 13-\mathrm{D}-20$ of 17.12 .2013 confirmed on that points by the court of appeal on 21.05.2015; A similar reasoning has also been used in some merger cases, for instance, in its EDF-Dalkia merger decision: European Commission, 'EDF/Dalkia en France', COMP/M.7137, dated 25.06.2014. 68 French Competition Authority, Decision $n^{\circ} 14-\mathrm{D}-06$, dated 08.07.2014, relative à des pratiques mises en œuvre par la société Cegedim dans le secteur des bases de données d'informations médicales. This decision has been confirmed on appeal but is still pending in front of the Cour de Cassation (the French Supreme Court). 
abuse and reference can be made to cases such as Commercial Solvents, ${ }^{42}$ Telemarketing, ${ }^{43}$ TeliaSonera ${ }^{44}$ Teléfonica ${ }^{45}$ and Microsoft ${ }^{46}$ where the conduct analysed is subordinate to the anticompetitive effects created by the dominant firm. ${ }^{47}$ The requirements for finding abuse under the monopoly-leveraging concept would then need a finding of two separate markets (data market and device market), a business strategy outside the notion of competition on the merits (right to use, lock-in, non-access to data, non-assert requirement, or discrimination in access to data) by the dominant Internet intermediary on the primary data market, subsequent entry onto the (competitive) secondary market either by the Internet intermediary or a proxy causing an exclusionary effect on that market by potentially foreclosing equal efficient existing competitors, and that there is no objective justification for not giving access to the data.

A leveraging test following the steps above implies that certain features need not be present or, for that matter, identified. The service provided does not need to be indispensable, and neither dominance on the secondary market nor elimination of competition on that market need be proven. These steps seem to be set in stone, yet, given that the underlying doctrine of Article 102 TFEU is uncertain, it should be admitted that the steps for a general leveraging test are, by the best estimate, ambiguous.

The current probes by the EU Commission and the German Bundeskartellamt of Amazon may soon address issues similar to what have been described above. According to interviews with Competition Commissioner Vestager, DG Comp opened a preliminary probe into Amazon's use of data on its third-party merchants. The idea was to assess the dual role of the e-commerce giant, given that it hosts but also competes against these other merchants. There are concerns that Amazon could be using sensitive information about its competitors' products to its own advantage. ${ }^{48}$ It seems that Amazon is using data it collects from

42 Case C-6/73 Istituto Chemioterapico Italiano and Commercial Solvents $v$. Commission ECLI:EU:C:1974:18.

43 Case C-311/84 CBEM v. CLT and IPB ECLI:EU:C:1985:394.

44 Case C-52/09 TeliaSonera Sverige ECLI:EU:C:2011:83.

45 Case C-295/12 P Telefónica and Telefónica de España v. Commission ECLI:EU: C:2014:2062.

46 Case T-201/04 Microsoft v. Commission EU:T:2007:289.

47 Thomas Hoppner, 'Duty to Treat Downstream Rivals Equally: (Merely) a Natural Remedy to Google's Monopoly Leveraging Abuse' (2017) 1(3) European Competition and Regulatory Law Review (CoRe) 208, available at SSRN: https://ssrn.com/abstract $=3040605$ accessed 23 June 2018 .

48 See EU Commission Press Release, Antitrust: Commission opens investigation into possible anti-competitive conduct of Amazon, 17 July 2019, available at http:// europa.eu/rapid/press-release_IP-19-4291_en.htm accessed 17 July 2019. 
its competitors' business transactions on Amazon, and uses that for setting up or intensifying its own competitive service or product line.

The German probe seems to supplement the EU Commission probe, and the German Competition Authority is looking at Amazon's terms of business and related practices which might be considered abusive, including liability provisions to the disadvantage of business users, in combination with choice of law and jurisdiction clauses, rules on product reviews, the non-transparent termination and blocking of sellers' accounts, withholding or delaying payment, clauses assigning rights to use the information material which a seller has to provide with regard to the products offered and terms of business on pan-European despatch. ${ }^{49}$ Moreover, the German Competition Authority indicates in reference to the issue of dominance that the business users are dependent on Amazon. Thus, the German Competition Authority finds indications both for dominant position and - even though such dominance will not be found - the business users using Amazon may still be so dependent on Amazon that in reference to their business relationship, Amazon may still hold power to the level where the German Competition law may still be triggered.

Utilising a leveraging test with a view to upholding interoperability and access to data tends to increase competition and innovation in the digital economy, and downstream. ${ }^{50}$ The remedy for a finding of abuse would be full contractual and technical interoperability and data access or - the other way around - that the dominant firm is restricted from accessing and using customers' data. Demanding that dominant firms give access for certain victims or even generally to create a 'data common', i.e. access for all to all data, would lessen network effects, tipping and the element of central planning, while intensifying competition and creating efficiencies on downstream device markets. This may feel awkward for an efficiency-oriented competition lawyer because it is akin to industry policy. Nonetheless, for markets plagued by network effects and tipping, protecting data access and interoperability under competition law may be key. Perhaps data access and interoperability can uphold competition to the extent that network effects are prevented and decrease the risk that the legislator will need to create data commons through sector-specific regulations.

Notwithstanding the above, it must be acknowledged that competition law is a heavy-handed instrument. The general text of Articles 101 and 102 TFEU indicates that they are primarily to be used ex post, and any clear doctrine takes

49 See the German Competition Authorities press release: https://www .bundeskartellamt.de/SharedDocs/Meldung/EN/Pressemitteilungen/2018/29_11_2018 _Verfahrenseinleitung_Amazon.html?nn=3591568 accessed 22 July 2019.

50 See early discussion regarding the findings by the economists Jens Prüfer and C. Schottmüller in Prüfer and Schottmüller (n 27). 
a long time to develop, given the perceived unavoidable litigation that will follow a decision by the Commission. Any new doctrine pursuing a new leveraging test for the digital market would take a long time to develop. Of course, the Commission may also use interim measures and merger control (ex ante) and sector- and market-specific investigations to develop new doctrine more quickly. However, as EU antitrust law stands today, with the exceptional circumstance doctrine and its high, market share-driven tests/barriers for showing dominance and rather limited set of conduct types defined as 'antitrust harms', gatekeepers are for now rather 'safe'. Their general business strategies based on indirect network effects and tipping will likely not be addressed under Article 102 TFEU.

Perhaps the current maladaptation of EU antitrust law is the reason why the Commission seems so keen to introduce sector-specific regulations in this field, in reference to both unfair competition and portability of data. However, competition law has a clear use and advantage and is a great tool for balancing pros and cons. A general abuse test with clear frames for the establishment of dominance could be the key for modernising antitrust law for the digital market, without enacting specific-sector regulations.

\section{SECTOR-SPECIFIC REGULATIONS AND DATA PROTECTION RULES}

Sector-specific regulations seem to be the tool to be used to create competition in the digital economy of the 21 st century and the Commission seems keen on using sector-specific regulations to solve some of the issues discussed above. Firstly, the EU has introduced a platform-to-business (P2B) Regulation, which targets the platform-business interface..$^{51}$

51 The Commission's roadmap or the P2B stated that the overall policy objective was to ensure a fair and innovation-friendly platform economy. More specifically, the aims for a $\mathrm{P} 2 \mathrm{~B}$, according to the Commission, should be a) to optimise the innovation and growth potential of online platform ecosystems, by securing a predictable business environment for firms depending on platforms and thus enhancing the general level of trust of all (potential) users; b) to limit direct negative effects of problems arising in platform-to-business relationships; c) to prevent, ex ante, abuse of dependencies in the platform economy; d) to reduce burdensome compliance costs derived from legal fragmentation, which could jeopardise the functioning of the Digital Single Market, and; e) to facilitate the emergence of new online platform firms, including by reducing barriers to entry and by ensuring a level playing field. European Commission, Fairness in platform-to-business relations, Ref. Ares(2017)5222469 - 25/10/2017, https://ec .europa.eu/info/law/better-regulation/initiatives/ares-2017-5222469_en, accessed 28 May 2018. 
The P2B Regulation mostly focuses on rules regarding transparency, and it seems clear that the P2B Regulation covers services provided by Internet intermediaries. The Commission in its proposal is somewhat reluctant and hesitant to regulate $\mathrm{P} 2 \mathrm{~B}$ in detail. ${ }^{52} \mathrm{P} 2 \mathrm{~B}$ Regulation addresses to some extent the problem with Internet intermediaries having access to more data than its customers. Article 7 of the P2B Regulation obliges providers of online intermediation services to provide business users with a clear description of the scope, nature and conditions of their access to use certain categories of data.

According to the regulation, the description should be proportionate and might refer to general access conditions, rather than an exhaustive identification of actual data, or categories of data, in order to enable business users to understand whether business users can use the data they have created with the provider of the online intermediation service, or not. Indeed, the provider of the online intermediation service is not obliged to give the customer (the business user) access to the data the user creates through his business on the platform. The data belongs to the Internet intermediary. Moreover, as may be derived from the GDPR, a business user also should, according to the P2B Regulation, be informed whether it has access to personal data or other data, or both, including in aggregated form, provided by or generated through the provision of the online intermediation services from all of the business users and consumers thereof, and if so, to which categories of such data and under what conditions. Indeed, the P2B Regulation implicitly states that the data generated by a business user on a platform belongs to the system leader.

Moreover, Article 6 of the P2B Regulation states that providers need to be transparent if they intend to discriminate in reference to access to data, by giving better access to affiliated firms then to the business user.

52 The Commission starts its proposal in a quite bold manner stating ' $t \mathrm{t}]$ hese online intermediation activities usually benefit from important data-driven direct and indirect network effects which tend to result in only a limited number of successful platforms per intermediated segment of the economy. This growing intermediation of transactions through online platforms, combined with strong indirect network effects that can be fuelled by data-driven advantages by the online platforms, lead to an increased dependency of businesses on online platforms as quasi "gatekeepers" to markets and consumers. The asymmetry between the relative market strength of a small number of leading online platforms - not necessarily dominant in the sense of competition law - is exacerbated by the inherently fragmented supply-side consisting of thousands of small merchants.' However, in the end the obligation to give business user access to term and conditions does not seem to be that intrusive. Cf. The proposed P2B regulation: Brussels, 26.4.2018 COM(2018) 238 final 2018/0112 (COD) Proposal for a regulation on promoting fairness and transparency for business users of online intermediation services. 
The P2B Regulation thus addresses the issue of data and who has access to it, while only providing rules regarding a right to be informed.

Secondly, notwithstanding the P2B Regulation, sector-specific regulations seem to be the preferred tool for giving business users, even competitors access to data. ${ }^{53}$ There are several specific directives and rules regarding, for example, public data, financial data, user-generated data originating from cars etc., which either have been recently implemented or are being developed in the EU. To a certain extent, they provide rights to access data, or embryos of such rights. ${ }^{54}$ Indeed, they are embryos of the 'data commons' where all firms have a right to access the data generated by the service or platform. They also are examples for the discussion in academia about creating access to data on a sector-by-sector basis, rather than creating generally applicable principles and doctrines. ${ }^{55}$

The PSI Directive, already mentioned, stipulates the route for accessing government data. The main focus of the PSI Directive is very specific. It is to create a level playing field when making available PSI as input to a commercial activity, i.e. when the PSI is used as components of new products and services. This should then release the full economic potential of a new emerging area of the ICT sector. ${ }^{56}$ If Public Sector Bodies (PSBs) offer information products or services exclusively, chances are that they will not be able to provide these services as innovatively and efficiently as a structure governed by competition would be able to. ${ }^{57}$ This could have a negative effect on competition in the European market. Therefore, the PSI Directive aims to overcome these barriers, which limit the re-use of PSI in EU Member States. The PSI Directive thereby stipulates public sector data collectors should grant access to data. The public sector data collector is even obliged to grant access

53 Regarding public sector data, financial data and eCall rules for cars, see, for example, Björn Lundqvist, 'Standardization for the Digital Economy: The Issue of Interoperability and Access Under Competition Law' (2017) 62(4) The Antitrust Bulletin 710.

54 Drexl mentions several legal initiatives, see Drexl (n 24) 12 et seq. See also Björn Lundqvist, 'Big Data, Open Data, Privacy Regulations, Intellectual Property and Competition Law in an Internet-of-Things World: The Issue of Accessing Data', in: Bakhoum M., Conde Gallego, B., Mackenrodt, M.-O., Surblytė-Namavičienè, G. (eds) 'Personal Data in Competition, Consumer Protection and Intellectual Property Law' (MPI Studies on Intellectual Property and Competition Law, vol 28. Springer, Berlin, Heidelberg), available at SSRN: https://ssrn.com/abstract=2891484 accessed 15 April 2018.

55 See, for example, Drexl (n 24) 12 et seq.

56 EU Commission, Public Sector Information: A Key Resource for Europe, Green Paper on Public Sector Information in the Information Society, COM(1998) 585 final, 5.

57 Lundqvist (n 5). 
if it re-uses data collected commercially by selling access to the database to data brokers or re-users. The PSI Directive tries to negate barriers which could include attempts by PSBs to charge supra-competitive prices, unfair competition between the public and the private sector, practical issues hindering re-use (like the lack of information on available PSI), and the attitude of PSBs failing to realise the economic potential of PSI. ${ }^{58}$ The PSI Directive is triggered by three sets of questions:

1. Are the data created (supplied) outside or inside the public task of the PSB? If so, what is the initial purpose for producing the data? Is it to fulfil a public task? If yes, the second question is:

2. Are the documents being re-used by the PSB or some other body on its behalf? In other words, will the data be used for another purpose than the initial purpose? Moreover, will this re-use constitute a commercial activity, for example giving access to the dataset to paying subscribers?

3. If so, then a number of requirements will apply, including that third parties have the right to access the dataset on something similar to FRAND terms, so as to enable the third parties to commercially utilise the Open Data in competition with the PSB and other firms having access to the dataset.

Interestingly, the PSI Directive seems to include non-discriminatory exclusion rules, similar to the ideas put forward in the French cases $G D F^{59}$ and $E D F .{ }^{60}$ Indeed, the PSI Directive stipulates a prohibition on governments and government authorities abusing the power inherent in the data collected, without the need to identify dominance in reference to the authority or the database.

The very interesting eCall Regulation ${ }^{61}$ should also be mentioned. According to Recital 16:

[i]n order to ensure open choice for customers and fair competition, as well as encourage innovation and boost the competitiveness of the Union's information technology industry on the global market, the eCall in-vehicle systems should be based on an interoperable, standardised, secure and open-access platform for possible future in-vehicle applications or services. As this requires technical and legal

${ }^{58}$ Katleen Janssen and Jos Dumortier, 'Towards a European Framework for the Re-use of Public Sector Information: a Long and Winding Road' (2011) 2 International Journal of Law and Information Technology 195.

59 French Competition Authority, Decision 14-MC-02 of 09.09.2014. The case is discussed in German and French Competition Authorities (n 14) 20.

${ }^{60}$ French Competition Authority, Decision n ${ }^{\circ} 13-\mathrm{D}-20$ of 17.12.2013, confirmed on that points by the court of appeal on 21.05.2015.

${ }_{61}$ Regulation (EU) 2015/758 concerning type-approval requirements for the deployment of the eCall in-vehicle system based on the 112 service and amending Directive 2007/46/EC [2015] OJ L 123/77. 
back-up, the Commission should assess without delay, on the basis of consultations with all stakeholders involved, including vehicle manufacturers and independent operators, all options for promoting and ensuring such an open-access platform and, if appropriate, put forward a legislative initiative to that effect. Furthermore, the 112-based eCall in-vehicle system should be accessible for a reasonable fee not exceeding a nominal amount and without discrimination to all independent operators for repair and maintenance purposes in accordance with ... [author's highlight]. ${ }^{62}$

The eCall Directive seems to lay the groundwork for a future where competitors are able to access data originating from cars used by individuals, the groundwork being that the device should be (connected to) a standardised, secure and open-access platform. Interestingly, the idea seems to be that by creating a standard, competitors will be enabled not (only) to produce eCall machines under FRAND licences, but to actually access eCall machines in the cars with their own applications so as to pick up data. The automobile manufacturers should, thus, not have an exclusive right to the personal data created in the car (the device), while possibly, opening up the platform in the car to, for example, leasing firms, insurance companies and independent service providers who should be able to access the device for collecting data. ${ }^{63}$

Finally, the recently updated Directive on Payment Services (DPS II) stipulates a right for third parties under certain circumstances to access the banking data of consumers. Consumers should be able to agree that third parties provide services, while accessing consumer bank accounts and Internet bank sites. DPS II may, to promote competition, require banks to provide standardised API access to third parties under the auspices of the European Banking Authority (EBA). ${ }^{64}$ This may enable third parties to tailor their banking services to customers, while using data collected by a competitor.

62 ibid.

63 An example of this development could be the AUDI AG, BMW Group, Daimler AG, Ericsson, Huawei, Intel, Nokia and Qualcomm Incorporated formation of the '5G Automotive Association', announced on 27 September 2016. The association will develop, test and promote communications solutions, support standardisation and accelerate commercial availability and global market penetration. The goal is to address society's connected mobility and road safety needs with applications such as connected automated driving, ubiquitous access to services and integration into smart cities and intelligent transportation. See https://www.ericsson.com/news/160927 -telecommunications-and-automotive-players_244039854_c accessed 23 June 2018.

64 See Directive (EU) $2015 / 2366$ on payment services in the internal market, amending Directives 2002/65/EC, 2009/110/EC and 2013/36/EU and Regulation (EU) No. 1093/2010, and repealing Directive 2007/64/EC (Text with EEA relevance) [2015] OJ L 337/35. Cf. EU Commission, 'A Digital Single Market Strategy for Europe', $\operatorname{COM}(2015) 192$ final. 
These four legislative acts are examples of rules that require fair terms for business users and to some extent require access to data or to devices/ platforms. It is possibly an indication of an interesting underlying current that the legislator is trying to boost competition by creating fair business terms and a level playing field, granting access to competitors' data, while circumventing general competition law. The idea is to boost competition, without making use of any test of antitrust harm, by opening up the device for collecting data to all and everyone. Whether such a policy is pro-competitive may be disputed. No competition harm analysed invited the possibility that an anti-competitive decision will be granted. Not only new entrants will be able to obtain data, also incumbent e-platform firms will try to access these devices or, in reference to government data, the public sector information. This may act as a deterrent for the brick-and-mortar industry firms to become full-fledged competitors in the data industry. Indeed, the incentive to become a member of the data industry may be low if a brick-and-mortar firm knows that it is obliged to share the input data, i.e. its raw material. Moreover, it also begs the question, to be put to the legislator, why similar access rules do not exist in other industries. Why does not the P2B Regulation stipulate a right to access data for business users?

\section{CONCLUSION}

Digitalisation, IT and the ability to store vast amounts of data have unleashed enormous potential for enhancing consumer welfare, reducing transaction costs and modernising new and old economies. Indeed, it is a paradigm shift which changes our notion of personal autonomy, self-determination and, in essence, the very definition of being human. The use of data implies the possibility for platforms to use central planning and that users will be outsourcing the task of taking decisions, both small and large, to digital ecosystems of information. That will affect the way we conduct business, but also our personality ${ }^{65}$ Moreover, it may have great implications for how we perceive competition between firms. Demand will not be based on individuals making independent decisions, but rather on the result of data analytics connected to an ecosystem individuals have been connected to from birth. ${ }^{66}$

Competition law protects to a certain extent variety, choice and innovation, but does not directly protect consumer autonomy and self-determination; rather it protects competition to the benefit of consumers. So, the element of

65 Michal Gal and Niva Elkin-Koren, ‘Algorithmic Consumers' (2016) 30 Harvard Journal of Law and Technology 309, available at SSRN: https://ssrn.com/abstract= 2876201 accessed 23 June 2018.

66 ibid. 
central planning is addressed under competition law rather as an access issue, that competitors should benefit from accessing customers, data or intermediaries, and that data holders or intermediaries should not leverage the inherent power of data and their role as gatekeepers vis-à-vis competitors to the extent that competition on the merits is infringed. Brick-and-mortar firms should be able to compete on a somewhat levelled playing field and not be degraded to suppliers or unequal partners of the platform operators, while the platform operator obtains all relevant data from the customers, suppliers and competitors of the brick-and-mortar firm. ${ }^{67}$ For this to happen we need to establish new tests. Perhaps the underlying doctrine regarding the PSI Directive could give some inspiration.

The PSI Directive seems to include non-discriminatory exclusion rules, similar to the ideas put forward in the French cases $G D F^{68}$ and $E D F^{69}$ discussed above. Indeed, the PSI Directive stipulates a prohibition on governments and government authorities abusing the power inherent in the data collected, especially when giving access on discriminatory terms, without the need to identify dominance in reference to the authority or the database. Perhaps, a similar doctrine could be developed under EU competition law. Nonetheless, the perceived problems with competition in the digital economy are centred around platforms and system leaders.

The perceived abuses in the digital economy seem to be centred around platforms. Platforms may be used to favour or discriminate to the benefit of affiliated or directly owned firms in downstream, neighbouring or upstream markets. Indeed, platforms that have gained leading positions in the ecosystem have the power to exclude competitors or to lock in customers or business users. In addition, their control and use of data regarding their customer and users, and their financial resources, contribute to their leading roles within their respective networks vis-à-vis business users. ${ }^{70}$ They may exploit customers and business users by utilising business strategies of, for example, personalised pricing, and exploitative tying, or by just knowing so much more about the customers of their competitors. However, if they are seen as regulators, the system leaders then need to treat their business users under something akin to

\footnotetext{
67 Lundqvist (n 18).

68 French Competition Authority, Decision 14-MC-02 of 09.09.2014. The case is discussed in German and French Competition Authorities (n 14) 20.

${ }^{69}$ French Competition Authority, Decision n ${ }^{\circ} 13-\mathrm{D}-20$ of 17.12.2013, confirmed on that point by the court of appeal on 21.05.2015.

70 Rupprecht Podszun, 'Innovation, Variety \& Fair Choice - New Rules for the Digital Economy: Expert Opinion for Finanzplatz München Initiative' (FPMI 2017) available at SSRN: https://ssrn.com/abstract=3243403 or http://dx.doi.org/10.2139/ ssrn.3243403 accessed 15 July 2019.
} 
FRAND terms. Indeed, the business users should be able to access and use the digital ecosystem on a level playing field.

To address the issue of platform-to-platform competition, we need to use general competition law to regulate the underlying conduct that triggers indirect (or direct) network effects and tipping, so as to prevent monopolies from being created, while still not killing the incentive for firms to pursue platform-to-platform competition. Moreover, the issue is whether we should turn on the firms that gain monopoly position due to indirect network effect and tipping. They have in one sense used economies of scale to gain this position. Yet, economies of scale on digital markets do not necessarily imply lower prices or, for that matter, greater efficiencies. Moreover, we know that the firms that have tipped digital markets and gained market power will most likely hold on to their position because it is very difficult to break a monopoly built on indirect network effect. ${ }^{71}$

In the United States, leading politicians have in light of the power of platforms and in relation to platforms participating as sellers on their own platforms called for the break-up of some technology companies. ${ }^{72}$ Also, participants in academia have expresssed similar views. ${ }^{73}$

A less intrusive way suggested in the EU Commission report 'Competition policy for the digital era', to resolve the issue of using network effect and tipping to gain monopoly power, is to utilise the principle of special responsibilities: that when a platform driven by indirect effect has been established, the system leader controlling the platform is allowed to continue having the platform, yet should be considered the regulator of the connected ecosystem or network. There will be little, if no, competition for that network or ecosystem and the system leader therefore has a special responsibility to create competition by creating a level playing field for downstream and connected markets, similar to that of a regulator. ${ }^{74}$

When a system leader has obtained the status of regulator of its ecosystem a higher degree of responsibility will be applicable. A regulator needs to be

71 Prüfer and Schottmüller (n 27).

72 In the United States, Senator Elizabeth Warren has expressed a view in relation to platforms participating as sellers on their own platforms in a call to break up some technology companies; see Colin Lecher, 'Elizabeth Warren says she wants to break up Amazon, Google, and Facebook: A proposal to unwind Big Tech' (8 March 2019 https://www.theverge.com/2019/3/8/18256032/elizabeth-warren-antitrust-google -amazon-facebook-break-up accessed 22 July 2019; and Nilay Patel, 'Elizabeth Warren Wants to Break Up Apple, too' (9 March 2019) https://www.theverge.com/2019/3/9/ 18257965/elizabeth-warren-break-up-apple-monopoly-antitrust accessed 22 July 2019.

73 Lina M. Khan, 'The Separation of Platforms and Commerce' (2019) 119 Columbia Law Review 973 available at SSRN: https://ssrn.com/abstract=3180174.

74 Crémer et al. (n 2) 69 et seq. 
fair, reasonable and apply principles of non-discrimination. Indeed, a multitude of conduct may be considered per se abuses depending on where to draw the line and what effects need to be proven. Preventing interoperability, access to ecosystems or IT systems and preventing portability of data would be considered abuses or monopolisation under such a higher degree of responsibility. Indeed, system leaders may have an obligation to welcome business users to its ecosystem, and treat them somewhat equally. Discrimination, by not creating a level playing field, or by not displaying similar business users, on equal terms, in search results or on product/services comparison sites may be an abuse. Indeed, platform neutrality could in one way be established based on competition law, depending how far the regulator role should be implemented. Both inter- and intra-platform competition could be enhanced by such a doctrine. 